\title{
Resiliência e polinização da música negra que vem ocupando os espaços urbanos do Rio de Janeiro
}

\author{
Micael Herschmann' \\ https://orcid.org/0000-0001-8859-0671 \\ Cíntia Sanmartin Fernandes" \\ https://orcid.org/0000-0002-7501-6387 \\ I - Universidade Federal do Rio de Janeiro. \\ Rio de Janeiro (RJ), Brasil. \\ II - Universidade Estadual do Rio de Janeiro. \\ Rio de Janeiro (RJ), Brasil.
}

Resumo: Tomando como referência observações de campo e matérias jornalísticas veiculadas na cena midiática, bem como a bibliografia especializada, busca-se neste artigo construir uma cartografia das controvérsias e realizar um breve balanço dos processos de glamourização e coibição (e até de criminalização) que vêm sendo associados às manifestações da música negra — tais como o samba, funk, jongo e hip hop - as quais vêm ocupando tradicionalmente os espaços públicos da cidade do Rio de Janeiro na forma de pequenos eventos. Parte-se do pressuposto de que tem sido especialmente nas rodas dessa metrópole (que gravitam em torno dos gêneros musicais mencionados acima), que os atores de diferentes segmentos sociais vêm conseguindo promover historicamente um conjunto de práticas culturais que geram não só resiliência, mas também polinização, as quais têm permitido construir territorialidades que vêm ressignificando o imaginário e, de modo geral, o cotidiano dessa urbe.

Palavras chave: comunicação; cultura; cidade; música; política.

Abstract: Resilience and pollination of black music that has been occupying urban spaces in Rio de Janeiro - Taking as a reference field observations and journalistic articles published in the media scene, as well as the specialized 
bibliography; this article seeks to build a cartography of the controversies and carry out a brief assessment of the processes of glamorization and restraint (and even criminalization) that have been associated with the manifestations of black music - such as samba, funk, jongo and hip hop -, which have traditionally occupied public spaces in the city of Rio de Janeiro in the form of small events. It is based on the assumption that it has been especially in the circles of this metropolis (which gravitate towards these musical genres mentioned above), that the actors from different social segments have historically managed to promote a set of cultural practices that generate not only resilience, but also pollination, which have allowed the construction of territorialities that have given new meaning to the imaginary and, in general, the daily life of this city.

Keyword: communication; culture; city; music; politics.

A cidade do Rio de Janeiro faz parte do circuito turístico de megaeventos espetaculares e globalizados há muitos anos, aspectos que evidentemente estão afetando a diversidade cultural e certas dinâmicas mais fluidas e informais presentes naquela localidade ${ }^{1}$. Além disso, o processo de construção de um regime menos democrático no Brasil (com a ascensão nos últimos anos de grupos de políticos associados a setores conservadores e religiosos do país) vem delineando um ambiente de mais vigilância social e de menos liberdade de expressão para as minorias, agravando ainda mais esse quadro.

Se levarmos em conta, por exemplo, a trajetória dos atores associados direta e indiretamente ao funk, samba, hip hop, jongo e outros gêneros da chamada música negra² que historicamente estão presentes nos espaços públicos dessa metrópole, constata-se que a maioria dessas manifestações e encontros são em geral protagonizados por uma população pobre e parda local $^{3}$. Ou melhor, é possível atestar: por um lado, que essas ocupações do espaço urbano são organizadas por iniciativa de artistas negros e mestiços que tradicionalmente vêm sendo perseguidos; e, por outro lado, que

1 Vale assinalar algumas considerações sobre os limites deste trabalho: a) a primeira é que se reconhece o impacto das políticas neoliberais adotadas que, por um lado, vêm facilitando excessivamente a circulação de conteúdo produzido pelos grandes conglomerados de comunicação e entretenimento; e que, por outro lado, vêm resultando em cortes no orçamento para apoiar e financiar a produção local; b) e a segunda é de que também se reconhece que as novas tecnologias têm produzido efeitos significativos no acesso ao conteúdo e na diversidade cultural.

2 Apesar de compactuar com as críticas feitas a este tipo de noção, adota-se e considera-se aqui como música negra aqueles gêneros musicais não só reconhecidos pelos atores enquanto tal (em geral utilizado em contraste com a música dos brancos), mas também aqueles ritmos identificados frequentemente com os processos históricos diaspóricos analisados por Paul Gilroy (2001) em seu livro seminal intitulado Atlântico Negro.

3 Vale sublinhar que - ainda que orientados e produzindo sentimentos de pertencimento e de identificação associados a esses grupos étnicos-raciais (afro-brasileiros) - esses eventos vêm acoIhendo recorrentemente segmentos sociais variados. 
esses encontros são considerados como uma evidência relevante de que a cidade do Rio persiste como uma cidade razoavelmente acolhedora e agradável de circular ${ }^{4}$.

Como interpretar essas dinâmicas culturais e a construção de imaginários tão díspares a respeito de uma mesma metrópole? Tal como é comumente rotulada na mídia: trata-se de uma cidade maravilhosa e/ou necessariamente partida (VENTURA, 1994)? Seria possível repensar essas perspectivas dicotômicas sobre a cidade?

Ao se buscar construir uma cartografia das controvérsias (LATOUR, 2012), teve-se como objetivo neste artigo repensar o papel da música - no caso a negra que ocupa os espaços públicos - como vetor de transformações sociais significativas, seja no plano concreto ou mesmo do imaginário urbano.

Desse modo, no presente artigo, parte-se do pressuposto de que, ao se problematizar a trajetória de algumas expressões da música negra (que ocupam as áreas da cidade do Rio de Janeiro), será possível compreender melhor de que maneiras essas iniciativas artísticas recorrentemente oscilaram entre a criminalização e a glamourização (artistas que, de modo geral, construíram uma trajetória errática e complexa, que articula e tensiona o êxito de mercado com uma condição muitas vezes proscrita) $)^{5}$, produzindo resiliências ${ }^{6}$ e

4 É uma metrópole que reúne historicamente muitos artistas de diferentes regiões do Brasil, mas também é uma cidade que possui certas características geográficas relevantes. Diferentes da maioria das cidades do país que são voltadas para a circulação rodoviária, essa metrópole possui um traçado em várias localidades e bairros que encoraja o tráfego de pedestres e uma dinâmica de trocas informais entre os habitantes da cidade, além de possuir um clima agradável e propício para a realização de atividades ao ar livre durante a maior parte do ano. Assim, é possível constatar que nessa urbe - que reúne uma quantidade expressiva de músicos - terminou por se desenvolver uma potente cultura da música de rua, a qual se expressa especialmente por shows, festas e rodas musicais, que ocupam esta cidade, com mais ou menos liberdade, desde o início do século XX (HERSCHMANN; FERNANDES, 2014).

5 Não se trata aqui de construir uma interpretação dicotômica da presença da cultura negra na vida social dessa cidade. Ao contrário, busca-se justamente enfatizar a complexidade que sobrepõe processos de marginalização e glamourização desses universos culturais (e, consequentemente, seus participantes diretos e indiretos). Por exemplo, Vianna (1999) e Herschmann (2000) ao analisarem a trajetória do samba e do funk respectivamente salientam que esses gêneros vêm se posicionando de forma ambígua nas bordas e fora do mainstream musical (o que não quer dizer que esporadicamente esse tipo de produção cultural não possa alcançar sucesso, isto é, produzir grande mobilização social e repercussão no mercado). Assim, ao mesmo tempo que o establishment oferece visibilidade e oportunidades no mercado, também persegue e critica os atores que integram essas cenas musicais.

6 O conceito de resiliência é apropriado do âmbito da psicologia e das ciências da saúde. Emprega-se o termo aqui como uma forma de sublinhar a capacidade dos atores em se adaptar frente às adversidades da vida urbana contemporânea - através de táticas e astúcias -, conseguindo assim dar vazão e continuidade a interesses, hábitos e práticas no cotidiano (TABOADA et al., 2006). 
polinizando ${ }^{7}$ o cotidiano dessa urbe.

Difundindo partilhas do sensível ${ }^{8}$ no dia a dia, esses pequenos e médios eventos (centrados especialmente nas rodas) contribuíram para que se conformasse conjuntos de narrativas da realidade sociocultural urbana muitas vezes bastante dispares, fazendo emergir discursos que ora sugerem articulações, ora tensões sociais: enunciados que vêm ganhando especialmente visibilidade nos meios de comunicação, os quais indicam ambiguidades no tratamento dessas práticas culturais.

Aliás, talvez por sua longevidade na história cultural brasileira, o gênero musical do samba e suas rodas — organizadas em espaços públicos e híbridos ${ }^{9}$ da cidade - exemplifiquem essas ambiguidades. Ao se analisar a trajetória do samba na época da Primeira República é possível atestar que, não só as populares rodas das tias baianas realizadas na região do Centro (da chamada

7 A noção de polinização cunhada pelo economista Moulier Boutang (2010) inspirou também algumas das reflexões desenvolvidas aqui. Esse autor identifica nesta prática interdependente diária das redes sociais esse tipo de trabalho que, como o das abelhas, não é reconhecido, mas é vital para o funcionamento do capitalismo contemporâneo. Como sabemos, a contribuição desses insetos para a polinização da biosfera é inestimável porque é crucial para a existência de vida no planeta. Da mesma forma, o poder das externalidades positivas produzidas pelas redes sociais é fundamental para a economia mundial: é aqui que grande parte da riqueza é explorada hoje, como evidenciado pelo desempenho dos grandes conglomerados de comunicação e entretenimento. Para seguir-se centrado no universo da música: pode-se dar o exemplo do carnaval de rua do Rio, que é um dos principais festivais populares do país, que envolve em média 5,5 milhões de pessoas todos os anos, e também baseado no ativismo da cultura de rua do Rio de Janeiro. O Estado, à semelhança das grandes empresas contemporâneas globalizadas, apropria-se das externalidades produzidas pelas redes musicais locais (HERSCHMANN; FERNANDES, 2014).

8 Para Rancière (2009), a estética revelaria a presença de mundos dissensuais dentro de mundos consensuais, evidenciando as tensões que constituem a política como forma de experiência. Assim, a estética como base da política só se dá a ver porque o político sempre está presente em questões ligadas a divisões e fronteiras, a uma partilha (que envolve, ao mesmo tempo, divisão e compartilhamento) da realidade social em formas discursivas de percepção que impõem limites à comunicabilidade da experiência daqueles que têm sua palavra excluída das formas autorizadas de discurso. Parte-se do pressuposto neste artigo que as experiências coletivas produzidas nos eventos de música negra promoveriam valores, códigos sociais e visões de mundo (éticas), fundando comunidades de partilha. Como salienta Marques, reavaliando alguns dos conceitos cunhados por Rancière: "a comunidade de partilha seria para o autor uma comunidade de experimentação e de tentativas de fazer com que realidades antes não imaginadas ou não associadas ao que é tido como 'comum' passem a aparecer e a serem percebidas, mas sem serem incorporadas, subsumidas, transfiguradas ou normalizadas" (MARQUES, 2011, grifo nosso).

9 Muitos especialistas em samba assinalam que as rodas locais seguem se instalando de modo geral em espaços públicos ou em outros nos quais é difícil precisar se são privados ou não. Quando analisamos as rodas seminais de grande popularidade que eram realizadas nas casas das tias ou mesmo aquelas que vêm ocupando hoje os bares e restaurantes dessa urbe, contatamos que em geral a maioria desses eventos — de ontem e hoje - invadem as calçadas, praças e becos, dificultando que se possa afirmar claramente onde começam as fronteiras do privado e do público. 0 que parece caracterizar esses encontros musicais é principalmente a ideia de fluxo e de uma circulação intensa dos atores nesses espaços (MOURA, 2009; SODRÉ, 1998). 
Pequena África), como também a participação frequente dos sambistas celebrando a Festa da Penha, foram marcadas por momentos e contextos de forte ambiguidade, nos quais o aparato policial ora tolerava as festividades, ora aplicava sanções junto aos atores.

Ao mesmo tempo, como recorda Sodré - ainda que em uma época préradiofônica - , o samba conseguiu ganhar espaços mesmo junto a segmentos sociais elitizados da época: não só tendo sido confundido com danças e ritmos amaxixados ${ }^{10}$, mas também ao conseguir seduzir os foliões durante os cortejos de carnaval (SODRÉ, 1998).

Pode-se ainda mencionar o lugar ambíguo ocupado por este gênero musical após a Revolução de 1930. Por um lado, atesta-se facilmente que o samba durante algum tempo foi tratado como espécie de inimigo do Trabalhismo Varguista (por sua recorrente associação ao mundo marginal da malandragem); mas, por outro, por conta da sua enorme popularidade muitas iniciativas foram feitas no sentido de incorporá-lo à cultura bem-conceituada daquela época: com a legalização e oficialização das escolas e do desfile de carnaval na cidade realizado pelo governo de Pedro Ernesto no início dos anos 30 do século XX; e, finalmente, o incentivo para que se elaborassem letras patrióticas e educativas de samba veiculadas nas principais rádios do país (MATOS, 1982).

Mesmo em períodos mais recentes pode-se encontrar indícios de que alguns artistas conhecidos e prestigiados, tais como Bezerra da Silva, Candeia ou Marcelo D2, tiveram alguns dos seus sambas questionados e criticados por tratarem de temas delicados e controversos; e que grandes eventos e festivais de samba seguiram sendo incorporados como parte de um conjunto de estratégias municipais para incrementar o turismo, ao mesmo tempo em que várias pequenas rodas de samba foram com alguma frequência proibidas em nome da preservação da ordem pública (FERNANDES et al., 2015).

Nesse sentido, o pressuposto central aqui é que, devido à sua grande capacidade de capilaridade e mobilização social, as expressões musicais - como manifestações estéticas e políticas (RANCIÈRE, 1996) - muitas vezes vêm permitindo a construção de territorialidades sônico-musicais (HERSCHMANN; FERNANDES, 2014) que alteram continuamente o ritmo

10 Vários autores relatam que o prestigio alcançado pelo samba e maxixe naquela época (nos valorizados salões da então capital do país), estaria relacionado a algumas turnês musicais bem-sucedidas em Paris (e outras cidades da Europa), realizadas nas duas primeiras décadas do século XX, que envolveram sambistas como Pixinguinha e Donga (liderando os Oito Batutas), Aguinaldo Guinle e os conhecidos dançarinos Duque e Gaby. Mais detalhes a este respeito conferir: SODRÉ, 1998. 
urbano, ressignificando o cotidiano, o imaginário e, em certa medida, as relações entre os atores no espaço urbano, principalmente quando esses estão presentes em áreas públicas das localidades. O que se busca destacar aqui é que para além da cidade dos megaeventos, espetacular e do branding territorial, há outra metrópole bastante popular, submersa e quase outsider ${ }^{11}$ que se faz também presente no cotidiano desse território (urbe que os atores seguem re-construindo até de forma heterotópica ${ }^{12}$ ): uma cidade que é incorporada apenas perifericamente no cartão postal dessa localidade e que gravita em torno de microeventos de rua organizados principalmente por coletivos artísticos que atuam de forma recorrente e significativa na trama urbana.

Por conseguinte, ao atuarem nas bordas ou para além dos limites da metrópole regulada (REIA et al., 2018), os indivíduos que imprimem ritmo às dinâmicas desses microeventos gratuitos (em geral, de características promotoras da inclusão social) vêm produzindo com frequência dissensualidades (RANCIÈRE, 1996). Pode-se dizer que, na qualidade de objetos/sujeitos que evidenciam controvérsias, os atores e seus pequenos eventos musicais que ocupam os espaços públicos do Rio contribuem para que os pesquisadores da Teoria AtorRede ${ }^{13}$ possam abrir algumas caixas pretas: quando esses seguem rastreando os atores nos seus itinerários e associações, cartografando uma determinada localidade (LATOUR, 2012; LEMOS, 2013).

\section{Resiliência da música negra no Rio de Janeiro hoje}

Apresenta-se aqui, de maneira breve, alguns exemplos recorrentes de ações coibitivas e resiliências que vêm ocorrendo nas últimas décadas.

O primeiro exemplo é o do universo funk carioca. Esta manifestação cultural vem sendo demonizada na grande imprensa (e pelos segmentos

11 Busca-se aqui enfatizar as várias facetas da vida urbana presentes no espaço do Rio de Janeiro, especialmente aquelas minoritárias, mas relevantes socialmente. Muitas vezes os grupos que promovem eventos de música negra que ocupam o espaço público são rotulados como tendo condutas marginais, clandestinas ou desviantes (HOBSBAWN, 1975; BECKER, 2008), pois apesar das normas, regulamentações e políticas públicas estabelecidas (e repressivas), seguem realizando certas práticas culturais (mesmo sem os alvarás concedidos pela prefeitura).

12 Emprega-se a noção de heterotopias não exatamente no sentido foucaultiano - como conjunto de práticas, na maioria das vezes, a serviço do biopoder (FOUCAULT, 2013) - e mais no sentido utilizado por Léfèbvre (2004) como iniciativas potentes, capazes de produzir linhas de fuga (DELEUZE; GUATTARI, 1995).

13 Quando o pesquisador-cartógrafo-formiga (que emprega a Teoria Ator-Rede) segue os atores, isto é, persegue aquilo que ainda não está estabilizado, ou seja, o que não é ainda propriamente consensual, eventualmente consegue abrir algumas caixas pretas em diferentes contextos. Busca-se realizar aqui uma cartografia das controvérsias - na medida em que esses são fenômenos ricos a serem observados na vida coletiva - explorando temáticas não consensuais, já estabilizadas socialmente. Mais detalhes ver: LEMOS, 2013. 
conservadores da população) há aproximadamente três décadas: não apenas por sua suposta associação com o crime organizado da cidade, mas também pelo ambiente gerado nos eventos que em geral é considerado excessivamente erotizado (e, portanto, suas festas vêm sendo coibidas por seus supostos efeitos nocivos sobre os jovens pobres da urbe). Com base nesses argumentos e sem o poder público oferecer alternativas, a maioria dos bailes funk das periferias e favelas estão inviabilizados há várias décadas na cidade do Rio (HERSCHMANN, 2000).

Evidentemente, setores progressistas da sociedade já estiveram mais articulados e empenhados em tentar legitimar culturalmente o funk ${ }^{14}$. Inclusive, em certo momento da história da cidade, essas iniciativas ganharam mais visibilidade social: não só pelo momento mais democrático que se vivia no país, mas especialmente por conta da grande popularidade do funk nas cenas juvenis, nas redes sociais e, de modo geral, no mercado ${ }^{15}$.

Entretanto, diferentemente dessa tendência, constatou-se que houve certo retrocesso no processo de legitimação sociocultural do funk durante o ano de 2019. As situações mais emblemáticas que indicam isso foram: a) a prisão arbitrária por quase seis meses, sem qualquer prova, do conhecido DJ Renan que se apresentava no Baile da Gaiola, o mais popular na cidade do Rio (e que até foi indicado para o Grammy Latino em 2019); b) e a ação repressiva do aparato policial em vários bailes funks de comunidades realizados nas periferias e favelas do Rio (tais como os que acontecem ainda hoje no Tabajara, Pavãozinho e Rocinha) ${ }^{16}$. Em um artigo publicado com grande destaque no El País - Brasil (ainda sob a comoção do massacre policial em Paraisópolis, São Paulo), o jornalista Gil Alessi faz o seguinte balanço:

[...] do samba ao funk, as manifestações culturais de origem negra e periférica no país vêm sendo reprimidas [...] [isto é,] ao longo da história [do país], expressões

14 No começo do século XXI, a Secretaria Municipal de Cultura do Rio chegou: a) a apoiar reuniões sistemáticas com lideranças do mundo funk carioca; b) a instituir editais públicos destinados a apoiar essas iniciativas culturais; c) e dar início ao processo de valorização do funk carioca como patrimônio imaterial local (LAIGNER, 2013).

15 Mesmo com a proibição dos bailes, o funk tem alcançado a condição de modismo entre os jovens no século XXI. O grande êxito - a) seja do funk melody, funk ostentação e funknejo; b) a grande circulação dos vídeos de dança do passinho; c) presença de artistas em eventos da grande mídia e em megafestivais; d) ou ainda de canais de Youtube como Kondzilla — são fortes indicativos disso (SÁ; CUNHA, 2014).

16 O incidente mais notório e que criou recentemente grande comoção social, entretanto, ocorreu em São Paulo: foi o da ação da polícia no Baile de Paraisópolis, que deixou inúmeros feridos e mataram nove jovens pobres e negros inocentes em nome da ordem pública. 
culturais de origem negra ou africana foram geralmente tratadas com violência pelas autoridades, que se esforçam para impedir a ocupação do espaço público a todo custo (ALESSI, 2019, p. 2).

Além desse exemplo, pode-se também mencionar a falta de apoio do governo municipal para a realização de rodas tradicionais de samba nas ruas da cidade, as quais diminuíram consideravelmente nos últimos anos. Apesar de todo o prestígio alcançado pelo samba (VIANNA, 1999), esse universo cultural também vem sofrendo sanções por parte do poder público, mesmo em suas práticas mais institucionalizadas e rentáveis para a cidade. Muitos dos coletivos artísticos - atuantes em rodas como, por exemplo, do Samba do Ouvidor, da Escravos da Mauá, da Pedra do Sal, do Samba do Trabalhador, entre outros - que organizam essas iniciativas reclamam da dificuldade não apenas em se obter autorizações para a realização das maiores rodas, mas também da concessão de pequenas estruturas para os eventos.

No entanto, no mundo do samba, o que tem chamado a atenção na atualidade é a maneira como o município tem dificultado sistematicamente a organização do carnaval oficial da cidade: não apenas a organização do carnaval de rua, mas até do desfile midiático das Escolas de Samba do Rio (ambos vendidos no mercado do entretenimento). Ainda que a cadeia de turismo da cidade dependa muito do sucesso anual do carnaval, os recursos financeiros para ajudar as escolas e os blocos de rua vêm diminuindo significativamente nos últimos anos. Em 2018, o clima de tensão entre os sambistas e poder público parece ter atingido o seu auge: vários grupos de rua tradicionais e até mesmo as escolas de samba (que têm seu desfile televisionado para vários países) só tiveram as suas autorizações e alvarás para se apresentar em espaço público liberados minutos antes de desfilar. É importante lembrar que os blocos e escolas de samba enfrentam inúmeras dificuldades logísticas na urbe, pois os seus cortejos costumam envolver milhares de pessoas (há blocos de carnaval que podem até mobilizar mais de um milhão de foliões em apenas um cortejo). Para muitos atores que atuam no carnaval, as motivações do prefeito do Rio em não apoiar o samba e carnaval da cidade seriam de caráter religioso ${ }^{17}$.

De fato, os efeitos negativos da interseção da política com o mundo religioso (lembrando que a chamada bancada evangélica está no poder em diversas 
cidades do Brasil) também vem afetando sobremaneira o desempenho das rodas musicais de Jongo (que apresentamos como um terceiro exemplo). Esse gênero musical e suas rodas, de grande tradição na cidade (considerado pelos historiadores da música como precursor do samba na cultura brasileira), suportam perseguições que vêm se intensificando nos últimos anos: em inúmeros relatos os atores salientam que seus eventos estão sistematicamente sofrendo sanções por parte das forças de segurança pública e por segmentos da população de orientação religiosa mais radical ou ortodoxa. O argumento acionado por aqueles que reivindicam a sua interdição é o de que as práticas culturais dessas rodas seriam um pretexto para a realização de práticas de magia negra. Ou seja, o jongo para estes atores não deveria ter qualquer prestígio e ser reconhecido como uma manifestação importante da tradição afro-brasileira pelas instituições públicas culturais (tal como ocorre em diversas delas), pois se trataria mais propriamente de um culto proscrito, o qual deveria ser necessariamente banido em nome da saúde pública (GRIESINGER, 2018).

E, finalmente, apresenta-se aqui uma última exemplificação (caracterizada também por perseguições e processos de glamourização): a do mundo do hip hop carioca. Apesar de algumas importantes conquistas alcançadas nos últimos anos ${ }^{18}$, inúmeros integrantes dessa cena cultural queixam-se - com frequência - de que eles não somente sofrem preconceitos e violências policiais (aspecto que dificulta a organização das rodas, mesmo aquelas que possuem alvarás $)^{19}$, como também reclamam da falta de apoios mais significativos por parte da prefeitura para os eventos (como, por exemplo, a oferta de editais públicos direcionados a este tipo de eventos ou mesmo de praticáveis e banheiros químicos) (SILVA, 2019).

18 No âmbito dessas conquistas e processo de legitimação poderia se mencionar: a) a institucionalização de uma semana comemorativa dedicada não de forma exclusiva ao hip hop (como manifestação cultural que integra o Circuito Carioca de Ritmo e Poesia) realizada anualmente entre os dias 25 a 31 de março; b) o reconhecimento das manifestações associadas a este gênero musical como parte dos patrimônios imateriais do Estado do Rio de Janeiro; c) e a inclusão de diversas rodas de hip hop (que celebram batalhas de freestyle) como parte integrante e relevante do CCRP. Ou seja, o hip hop alcançou algum reconhecimento institucional local por conta de uma aliança construída com o poder público municipal, através de um trabalho de mediação feito pelo CCRP (que acolheu as rodas hip hop). É importante salientar que o CCRP é um projeto que tem como objetivo "ocupar as ruas por meio da promoção do encontro de artistas sem reconhecimento da mídia e outras instâncias de legitimação", como é o caso do hip hop. O CCRP (que acolhe também iniciativas de poetry slam, rodas de rima, artes visuais, teatro, etc.) vem adquirindo envergadura e está funcionando há alguns anos como uma instância de negociação dos artistas que atuam na rua com o poder público, isto é, a partir dessa iniciativa se conseguiu algum reconhecimento por parte da Secretaria Municipal de Cultura (de que as rodas culturais que congregam estes artistas têm relevância e legitimidade para o setor cultural). Assim, inúmeras rodas (inclusive as de hip hop) — que se cadastraram no CCRP e na SMC — passaram a conseguir as autorizações para a sua realização (CURA, 2019).

19 Algumas matérias jornalísticas que exemplificam essas adversidades frequentes enfrentadas pelo hip hop: LUCAS, 2017; SALINAS, 2016. 


\section{Polinização musical da cidade do Rio de Janeiro}

Evidentemente, reconhece-se o momento muito particular e delicado que se está vivendo atualmente na história política brasileira, inclusive, a obstacularização sistemática às manifestações culturais no Rio e, em geral, no Brasil, tem começado a atrair também a atenção da imprensa internacional ${ }^{20}$.

Se, de modo geral, as manifestações culturais do país mais integradas ao mainstream têm sofrido perseguições, o que dirão aquelas que estão identificadas com os segmentos minoritários do país. Assim, nos últimos anos, a música executada nas ruas é cada vez menos valorizada como uma riqueza cultural local pelos órgãos de cultura dos governos municipais. Na mesma toada, os segmentos juvenis (que, em geral, promovem esses eventos musicais) passam crescentemente a ser vistos com mais desconfiança pelo poder público (no limite esses atores são considerados transgressores e até criminosos): isso se reflete nas narrativas que circulam na mídia e nas medidas coibitivas adotadas. Portanto, com o endurecimento das políticas de segurança pública e a falta de apoio às iniciativas socioculturais da população (com grande dificuldade de obter autorizações para pequenos eventos de rua), a maioria dos microeventos musicais e artísticos tendem, com o tempo, a se tornar clandestina ou mesmo ilegal. ${ }^{21}$

Também é importante notar que vários bairros da cidade vêm experimentando um intenso processo de gentrificação de seus espaços nos últimos anos. O município está tentando reverter aspectos negativos da imagem do Rio e atrair investimentos, apostando em estratégias de city marketing que visam transformar esse território em uma localidade mais globalizada, mais intensamente direcionada ao entretenimento e ao turismo. Ao mesmo tempo, nesta última década, tivemos a oportunidade de observar as crescentes tensões e conflitos nos quais inúmeros atores saíram às ruas para denunciar a dimensão exclusiva das grandes reformas urbanas que foram implementadas (JENNINGS et al., 2014).

Um dos pressupostos desta investigação é o de que o direito à cidade e o lazer vêm sendo negados à maioria da população do Rio, a qual é também

20 Algumas das matérias de destaque na imprensa internacional que exemplificam as dificuldades pelas quais passa o setor cultural do país: GATINOIS, 2019; PHILIPPS, 2020; LONDOÑO, 2020.

21 Alguns exemplos de matérias jornalísticas que indicam práticas coibitivas ou a construção de imaginário tendencialmente criminalizado: LANG, 2017; ANTUNES, 2017; SANCHEZ, 2019; PM TENTA, 2019; PM REPRIME, 2019. 
a mais pobre, negra e mestiça. O objetivo deste trabalho é avaliar de que maneira esses grupos musicais e suas redes desenvolvem astúcias e táticas (DE CERTEAU, 1994) para enfrentar as proibições e perseguições do poder público. Ou seja, apesar de tudo, pode-se dizer que os atores — de forma resiliente (TABOADA et al., 2006) - continuam promovendo a música de rua e seguem de forma criativa polinizando o cotidiano e construindo importantes dinâmicas de encontros na urbe (em suma, seguem promovendo significativas experiências político-estéticas inclusivas e democráticas).

Na realidade, para além das perseguições sistemáticas sofridas pela cultura negra na cidade do Rio (que é um pouco lugar comum na análise de especialistas), os conceitos de resiliência e polinização são cruciais para compreender o papel fundamental dessas expressões culturais que tiveram uma trajetória marcada por um movimento ambíguo e complexo, que simultaneamente criminaliza e glamouriza essas expressões musicais na cena midiática (HERSCHMANN, 2000).

Ao mesmo tempo, há que se reconhecer que gêneros musicais como, por exemplo, o samba e o funk estão entre os mais perseguidos pela crítica especializada e pelo aparato de segurança pública ao longo da história do país, expressando interesses e preconceitos de setores elitizados e/ou conservadores da população local. As proibições de festas, bailes e rodas ao longo de várias décadas, baseadas em inúmeras justificativas (que curiosamente nunca são aplicadas com rigor a atores considerados problemáticos, oriundos da classe média), são evidências significativas.

Entretanto, considerar apenas esse aspecto é não levar em conta outras dimensões dessas imbricadas trajetórias: as manifestações da cultura negra mencionadas neste artigo e seus protagonistas também foram valorizados como produção cultural pelo mercado 22 e pelas instituições (pelo menos aquelas dirigidas por atores com orientação política mais progressista), ocupando espaços nos cadernos culturais na mídia mais tradicional e alternativa (alcançando em alguns momentos a condição de modismos, os quais difundiram ritmos, roupas e acessórios, danças, linguagens e, de modo geral, códigos e valores sociais). Ainda que isso possa gerar alguma surpresa, quando se considera as trajetórias bem-sucedidas de artistas como Pixinguinha, Mestre Darcy Monteiro, Bezerra da Silva, MV Bill, Annita, Karol Conka ou DJ Renan, constatamos que todos eles tiveram carreiras que foram marcadas,

22 Ainda que os preconceitos continuem socialmente presentes, é inegável que existe mais mercado - inclusive em âmbito global - para os chamados gêneros musicais populares periféricos (TROTTA, 2013), protagonizada por esses atores. 
em alguns momentos, por situações de reconhecimento ${ }^{23}$ e, em outros, por questionamentos, perseguições e/ou até censuras a seus trabalhos.

Portanto, vale salientar a capacidade de resiliência da cultura negra carioca ${ }^{24}$, mesmo em ambientes menos democráticos (seja no período do Estado Novo, da Ditadura Militar e mesmo hoje): a capacidade desses atores em continuar a realizar eventos (em espaços híbridos e públicos), isto é, a disposição em persistir de forma tática e submersa, a habilidade de se adaptar à condição de clandestinidade, tornando-se praticamente invisíveis ao radar das políticas públicas.

É possível afirmar também que o trabalho colaborativo dos atores (aquilo que Moulier Boutang chama de apieconomia), vem polinizando e atualizando as práticas e tradições de rua carioca, as quais são fundamentais para a construção da rica vida sociocultural da cidade ${ }^{25}$. Aliás, nos últimos anos, ao dar as costas à sociedade pólen do Rio de Janeiro, ou melhor, ao gentrificar localidades e impor uma série de dinâmicas de regulação e repressão em diferentes espaços públicos da cidade, o Estado vem prejudicando o funcionamento de circuitos urbanos mais fluidos, democráticos e criativos de forma significativa.

No entanto, diferentemente das abelhas (MOULIER BOUTANG, 2010), os artistas e suas redes não cessam de polinizar de forma resiliente, estabelecendo alternativas de ocupação da cidade. Nesse sentido, pode-se sublinhar aquilo que foi identificado nas fontes históricas, conversas informais com os atores e observações de campo realizadas ${ }^{26}$ : que essas redes musicais (que

23 Evidentemente, o interesse e a grande adesão de fãs e consumidores têm sido relevantes nos processos de legitimação: não só de dessas manifestações como patrimônios culturais locais, mas também da carreira desses artistas. De certa forma, eles alcançaram a condição de porta-vozes e/ou de referências para segmentos da populaçãao negra e pobre carioca (HERSCHMANN, 2009).

24 Poder-se-ia mencionar alguns exemplos de rodas e bailes de razoável longevidade na história dessa urbe. Talvez os eventos mais emblemáticos dessa resiliência sejam o Samba do Trabalhador, as Rodas de Samba da Pedra do Sal e o Baile Funk da Rocinha.

25 Para se ter uma ideia do volume e da relevância dos pequenos eventos musicais que ocupavam a cidade do Rio antes de 2016, conferir a plataforma digital (cartografia musical) elaborada pelos autores, disponível em <http://www.cartografiamusicalderuadocentrodorio.com>, último acesso: 12.07.2019.

26 Desde 2012 vêm se pesquisando de forma sistemática (com apoio do CNPq, FAPERJ e CAPES) não só as rodas de rua de samba e jongo, mas também alguns bailes de charme, funk e soul da cidade (expressa-se aqui o agradecimento a estas agências de fomento à pesquisa por esse precioso apoio). Poder-se-ia mencionar como exemplos de eventos que estão sendo não só pesquisados (e alicerçam as reflexões desenvolvidas neste artigo), mas que também ocupam (e polinizam) os espaços públicos e, de modo geral, os espaços híbridos do Rio: Samba da Ouvidor, Jongo da Lapa, Baile do Viaduto de Madureira, Baile Black Bom, Roda de Samba da Pedra do Sal, Baile da Gaiola e Baile da Rocinha, entre outros. Aliás, salienta-se que os autores (ao longo desses anos) têm realizado com regularidade observações de campo e conversas informais com os atores que frequentam esses eventos. 
envolveram artistas, produtores culturais e frequentadores) - mesmo aquelas organizadas com atores mais pobres - seguem encontrando maneiras de resistir (ou re-existir), apesar da violência do Estado: ou seja, continuam se organizando em encontros culturais clandestinos com grande capacidade de mobilização da população da cidade. Ou melhor, como já foi mencionado anteriormente, o que se nota analisando a história urbana é que esses microeventos estão frequentemente estruturados na forma e dinâmica de rodas de rua.

Aliás, uma das hipóteses que orienta esse estudo é a de que as rodas são fundamentais para que se possa compreender o engajamento dos atores e a capacidade de resiliência e de polinização da cultura negra que ocupa a trama urbana carioca. A despeito dos regimes mais ou menos democráticos a que a população da metrópole do Rio de Janeiro (de ontem e hoje) é submetida, poderia se afirmar que esse território não vem se organizando e nem é imaginado de forma ainda mais segregada em razão da presença dessa potente cultura de rua, acessível aos diferentes segmentos sociais, e a qual tem como epicentro em geral a prática das rodas ${ }^{27}$.

Não se trata aqui de (re)construir uma perspectiva quase romantizada ou heroica dos protagonistas das rodas musicais (MOURA, 2004; TROTTA, 2019). Monetizada ou não, busca-se valorizar a sua potência e aspectos ritualísticos (GONÇALVES; CARVALHO, 2014). Quando se pensa em manifestações da cultura negra frequentemente também as associamos às práticas religiosas afro-brasileiras, nas quais a roda é acionada como estrutura e dinâmica. No entanto, o ponto que gostaríamos de sublinhar é que o ritual da roda é valorizado pelos membros de redes e coletivos musicais - que gravitam em torno de sonoridades e ritmos - porque se constitui em uma possibilidade de performatização (ZUMTHOR, 2007) da vida cotidiana e de construção de dinâmicas de reterritorialização e agenciamento dos espaços (DELEUZE; GUATTARI, 1995). Nesses rituais culturais, ainda que haja uma dimensão religiosa presente de forma difusa (TURNER, 1974), a criatividade se faz no jogo e na tensão com as regras, as quais regem as relações cotidianas e é, justamente, nessa inversão que o ritual-performance apresenta sua face transformadora. Se por um lado, o espaço da roda é estruturalmente idêntico quando é empregado; por outro, cada roda é única, constrói uma experiência não reproduzível. Isso se dá, principalmente, por conta da forma em que a roda se constrói, estabelecendo circularidades de fluxos e ajustamentos. 
O sentido do corpo na roda se molda a partir da sua compreensão enquanto lugar físico e da construção simbólica da identidade pessoal, marcando a fronteira entre o eu e o outro.

As fronteiras, simbólicas e físicas, da roda são, portanto, delimitadas pelos corpos que dela participam: atores e histórias que constroem e atualizam um lugar na trama urbana. Na roda há narrativas que se atravessam na construção de um território simbólico que representa, ao mesmo tempo, um mergulho em si mesmo e no outro (GONÇALVES; CARVALHO, 2014). Para além dos limites da roda, a ação do corpo em performance se dá, também, na ressignificação do espaço físico e real onde este território é construído. $O$ sujeito se compõe e se transforma na roda, e, pode-se dizer também, que a roda se compõe e se transforma na rua. Os atores inscrevem a cultura nas ruas através dos corpos e suas extensões: palavras, ritmos lentos e vozes são desdobramentos da corporeidade que completam a sua dimensão simbólica e reforçam a performance enquanto ação sociocultural de afirmação e transformação das ruas. Assim, os desdobramentos do corpo na performance da roda colocam em evidência a tomada temporária do espaço da rua em um sentido físico e simbólico.

Pode-se afirmar que as performances em roda ritualizam a ocupação desses espaços opacos ${ }^{28}$, ressignificando-os. Essas artes e práticas do fazer-com desses atores nos eventos musicais, em suas corporeidades desaceleradas (em relação ao ritmo das cidades) - baseadas nas trocas sensíveis e emocionais -, provocam transmutações no ritmo urbano ao se inscreverem nas brechas do tempo fundando lugares"29. Assim, "entre resistências e existências [...] os homens-lentos seguem transformando suas fragilidades em força" (VIDAL, 2020, p.197, tradução nossa).

\footnotetext{
28 Para Santos (2002), os espaços opacos seriam aqueles que se opõem aos espaços luminosos. No entanto, para tratar dessa oposição é necessário compreender que os espaços luminosos indicam "[...] a força da racionalização emanada do pensamento instrumental, que, ao selecionar o que tem ou não valor, é capaz de seduzir e convencer [...]. [Já os espaços opacos] são representados como feios, sem interesse ou perigosos pelo pensamento dominante, pois oferecem materializações de racionalidades alternativas e saberes relacionados à apropriação socialmente necessária dos recursos disponíveis, possibilitando a sua multiplicação. São espaços com menos técnica e mais inventividade, com menos dominação e mais domínio [...], os quais instauram o enigma da invisibilidade [...]. Seriam espaços abandonados por sucessivas modernizações [...] tratam-se de espaços de vida [...] e de sobrevivência de muitos outros" (RIBEIRO, 2012, p. 67-68).

29 Após o advento da globalização e todas as consequências advindas, pesquisadores das áreas da Sociologia e Geografia Cultural têm se debruçado sobre o estudo dos espaços-tempos e suas especificidades sócio-comunicacionais. Trabalha-se aqui a noção apresentada por Santos para quem os lugares seriam os espaços afetivos que tomam forma à medida que são experienciados, sensivelmente e inteligivelmente (SANTOS, 2002).
} 
Além disso, a participação habitual nas rodas musicais é frequentemente associada como um indício do compromisso dos atores com certa cena cultural (não necessariamente envolve artistas profissionais do mundo da música ou é um evento que integra a agenda profissional de alguém). De modo geral, os participantes amadores e profissionais das rodas podem se mesclar em um ambiente valorizado pela autenticidade (PEREIRA, 2003). Tendo em vista o engajamento recorrente dos atores nestas redes musicais (e seus microeventos) - compromissadas especialmente com a valorização da cultura negra e a democratização do acesso aos espaços e à vida cultural da urbe -, em trabalhos anteriores chegamos a denominar este tipo de atuação como uma forma de ativismo musical (HERSCHMANN; FERNANDES, 2014), ou melhor, de artivismo (VIEIRA, 2011).

Aliás, qual seria o lugar das rodas e da cultura musical de rua carioca no projeto de metrópole atual? De certa forma, podemos dizer que as metas para o Rio para os próximos anos parecem estar traçadas pelas autoridades: a cidade deve se transformar através de megaeventos em uma "cidade espetacular, criativa e globalizada"30. Entretanto, os megaeventos como um conjunto de estratégias exclusivas e redentoras - que promovem o crescimento econômico e social a médio prazo - têm sido questionados por especialistas e expressivas parcelas da população justamente por não terem trazido ainda os resultados esperados para a cidade do Rio ${ }^{31}$.

Ao mesmo tempo, no contexto atual pode-se atestar que o poder público municipal vem promovendo um grande curto-circuito ao desprezar com regularidade o minoritário, o múltiplo, o polifônico e as diferenças sublinhadas pelas expressões culturais. De forma similar a outros momentos do passado desta urbe, as rodas e as manifestações da cultura negra de rua são colocadas à margem ou excluídas dos projetos urbanos em curso. Assim, esses microeventos públicos e gratuitos, na qualidade ecossistemas culturais, seguem a sua trajetória de maneira quase clandestina na trama urbana,

30 O Plano Estratégico 2009-2012 da cidade do Rio deixa clara a importância da cultura na reestruturação urbana e no preparo do ambiente para os megaeventos internacionais. O documento estabelece como principal diretriz para orientação das políticas culturais: "o fortalecimento da metrópole do Rio de Janeiro como referência cultural do país através da revitalização patrimonial, requalificação urbana e promoção da diversidade" (Disponível em: <http://www.rio.rj.gov.br/dlstatic/10112/6616925/4178940/planejamento_estrategico_site_01.pdf>. Acesso em: 1 out. 2019).

31 Cresce o número de críticos que indagam se não deveria haver uma maior coordenação por parte do Estado da agenda cultural da cidade (em diversos âmbitos): de modo que se apoiasse e promovesse uma maior integração e sinergia entre os micros e megaeventos realizados na cidade do Rio de Janeiro, levando-se em consideração a vida cultural já existente no cotidiano (JENNINGS et al., 2014). 
gravitando em torno de eventos de jongo, samba, funk, hip hop e outros gêneros musicais da música negra.

\section{Considerações Finais}

Esse cenário de incertezas, articulações e controvérsias vêm se intensificando nos últimos anos na urbe, colocando em evidência uma multiplicidade de práticas culturais, narrativas e imaginários que contribuem para que se compreendam as dinâmicas socioculturais urbanas a partir de sua polifonia. Ao se abrir a caixa preta e se cartografar essas práticas e imaginários observam-se repertórios discursivos que constroem interpretações ambíguas dessa urbe.

Como se pode constatar ao longo deste artigo, em alguns discursos sugere-se uma cidade caracterizada não só pelas intervenções urbanas (que excluem e/ou criminalizam os segmentos mais pobres da população), mas também pela velocidade, impessoalidade e saturação. Seria o Rio globalizado, dos grandes concertos e megaeventos espetaculares. Em certo sentido, reitera-se nessas narrativas um imaginário da metrópole mais visível: a cidade do medo, segregada e do privilégio, do planejamento tecnocrático, a urbe onde impera a lógica funcionalista e econômica.

No entanto, há um conjunto de narrativas que se ancora em outros imaginários, os quais fazem referência a uma (ou várias) cidade(s) que persiste(m), apesar de tudo, que se faz(em) presentes nos espaços opacos, nos interstícios do espaço-tempo velozes das urbes contemporâneas e de maneira quase invisível: fazem alusão a uma urbe onde os atores promoveriam cotidianamente uma dinâmica mais espontânea e fluida, na qual emergem - por meio das trocas entre diferentes extratos sociais - experiências agradáveis, desaceleradas e de grande capacidade de mobilização social. Esses discursos fazem referência mais diretamente a relevância dos microeventos musicais presentes no dia a dia — os quais fundam partilhas do sensível (RANCIÈRE, 2009) - que possibilitam aos habitantes compartilharem valores sociais e ressignificarem os espaços da urbe $^{32}$, construindo assim uma cidade também aberta aos encontros e trocas.

Micael Hershmann é professor titular do PPGCom da UFRJ, onde dirige o Núcleo de Estudos e Projetos em

32 Sublinha-se que é muito comum as narrativas de mais visibilidade na cena mediática desconsiderarem a potência do existir dos habitantes locais, os quais seguem através dos pequenos eventos transformando, ao longo da história, resistência em re-existência. 
Comunicação. É doutor em comunicação pela mesma instituição.

micaelmh@globo.com

Cíntia Sanmartin Fernandes é professora do PPGCOM da UERJ, onde é coordenadora adjunta do Grupo de pesquisa Comunicação, Arte e Cidade. É doutora em Sociologia Política pela UFSC.

cintiasan90@gmail.com

Contribuição de cada co-autor: Micael Herschmann ficou responsável: Supervisão e Gestão do Projeto de Pesquisa; Curadoria de dados; gestão de recursos da pesquisa; e revisão do artigo. Ambos realizaram juntos a investigação de campo e a primeira e segunda redação do texto. Cíntia S. Fernandes ficou responsável: Fundamentação teórica e conceituação; e Análise Formal do Corpus; ajustes e edição do artigo solicitadas pelos avaliadores. Ambos realizaram juntos a investigação de campo e a primeira e segunda redação do texto.

\section{Referências}

ALESSI, G. Do samba ao funk, o Brasil que reprime manifestações culturais de origem negra e periférica. El País Brasil, Sociedade, 7 dez. 2019. Disponível em: <https://brasil. elpais.com/sociedade/2019-12-07/do-samba-ao-funk-o-brasil-que-reprime-manifestacoes-culturais-de-origem-negra-e-periferica.html>. Acesso em: 4 fev. 2020.

ANTUNES, T. Polícia Militar impede realização da roda de samba Pede Teresa. O Dia, Rio de Janeiro, 29 jul. 2017. Disponível em: <https://odia.ig.com.br/rio-de-janeiro/2017-07-29/ policia-militar-impede-realizacao-da-roda-de-samba-pede-teresa.html>. Acesso em: 21 nov. 2019.

BECKER, H. Outsiders. Rio de Janeiro: Zahar, 2008.

BHABHA, H. O local da cultura. Belo Horizonte: Ed. UFMG, 1998.

CARVALHO, F.; GONCALVES, R. O corpo na rua: a linguagem das performances nas Rodas Culturais. Artefactum, Juiz de Fora, v. 8, n. 1, 2014.

CURA, T. Minas de Batalha: feminismo(s) em rodas de ritmo e poesia. 2019. Dissertação (Mestrado em Comunicação) - Escola de Comunicação, Universidade Federal do Rio de Janeiro, Rio de Janeiro, 2019.

DE CERTEAU, M. A invenção do cotidiano. vol. 1. Petrópolis: Vozes, 1994. 
DELEUZE, G.; GUATTARI, F. Mil platôs. São Paulo: Ed. 34, 1995.

FERNANDES, C.; TROTTA, F.; HERSCHMANN, M. Não pode tocar aqui. E-Compós, Brasília, v. 18, n. 2, 2015.

FOUCAULT, M. O corpo utópico, as heterotopias. São Paulo: N-1, 2013.

GATINOIS, C. Au Brésil, le gouvernement Bolsonaro malmène la culture. Le Monde, Le mag, 16 mai. 2019. Disponível em: <https://www.lemonde.fr/m-le-mag/article/2019/05/16/ au-bresil-le-gouvernement-bolsonaro-malmene-la-culture_5462898_4500055.html>.

Acesso em: 03 fev. 2020.

GILROY, P. Atlântico negro. São Paulo: Ed. 34, 2001.

GRIESINGER, D. Produtores culturais e alunos protestam no Rio em defesa da Casa de Jongo. Agência Brasil, 9 jan. 2018. Disponível em: <https://agenciabrasil.ebc.com.br/ cultura/noticia/2018-01/jongueiros-protestam-no-rio-em-defesa-de-salvaguarda-para-o-patrimonio>. Acesso em: 24 abr. 2020.

HERSCHMANN, M. O funk e o hip hop invadem a cena. Rio de Janeiro: Ed. UFRJ, 2000.

. Ciudadania y estética de los jóvenes de las periferias y favelas In: MARTíN-BARBE$R O$, J. et al. (eds.). Entre saberes desechables y saberes indispensables. Bogotá: CCAL, 2009, p. 121-160.

.; FERNANDES, C. Música nas ruas do Rio de Janeiro. São Paulo: Ed. Intercom, 2014.

HOBSBAWN, E. Bandidos. São Paulo: Forense Universitária, 1975.

JENNINGS, A. et al. (orgs.). Brasil em jogo. São Paulo: Boitempo, 2014.

LAIGNIER, P. Do funk fluminense ao funk nacional: o grito comunicacional de favelas e subúrbios do Rio de Janeiro. 2013. Tese (Doutorado em Comunicação) — Escola de Comunicação, Universidade Federal do Rio de Janeiro, Rio de Janeiro, 2013.

LANG, M. Ocupar ou não ocupar: rodas de samba e eventos de rua enfrentam restrições no Rio. UOL Notícias, Rio de Janeiro, 3 nov. 2017. Disponível em: <https://noticias.uol. com.br/cotidiano/ultimas-noticias/2017/11/03/ocupar-ou-nao-ocupar-rodas-de-samba-e-eventos-de-rua-enfrentam-proibicoes-no-rio.htm>. Acesso em: 20 nov. 2019.

LATOUR, B. Reagregando o social. Salvador: EDUFBA, 2012.

LÉFÈBVRE, H. A Revolução Urbana. Belo Horizonte: Ed. UFMG, 2004.

LEMOS, A. Comunicação das Coisas. São Paulo: Annablume, 2013.

LONDOÑO, E. Speech Evoking Nazi Propaganda. New York Times, 17 de jan. 2020. Disponível em: <https://www.nytimes.com/2020/01/17/world/americas/roberto-alvim-brazil. html?>. Acesso em: 28 abr. 2020. 
LUCAS, Á. Rodas culturais de hip hop se queixam de burocracia para realizar encontros. O Globo, Rio, 22 jun. 2017. Disponível em: <https://oglobo.globo.com/rio/bairros/rodas-culturais-de-hip-hop-se-queixam-de-burocracia-para-realizar-encontros-21499684>. Acesso em: 29 abr. 2020.

MARQUES, A. Comunicação, estética e política. Galáxia, São Paulo, n. 22, 2011.

MATOS, C. Acertei no milhar. Rio de Janeiro: Paz e Terra, 1982.

MOULIER BOUTANG, Y. L'abeille et l'économiste. Paris: Carnets Nord, 2010.

MOURA, C. Blocos de carnaval não oficiais serão multados pela Prefeitura do Rio: querem 'baderna', diz secretário. G1, Rio de Janeiro, 12 fev. 2020. Disponível em: <https://oglobo. globo.com/rio/carnaval/blocos-de-carnaval-nao-oficiais-serao-multados-pela-prefeitura-do-rio-querem-baderna-diz-secretario-24244464>. Acesso em: 11 abr. 2020.

MOURA, R. No princípio, era a roda. Rio de Janeiro: Rocco, 2004.

PEREIRA, C. Cacique de Ramos. Rio de Janeiro: E-Papers, 2003.

PHILIPPS, T. Bolsonaro government attacks Oscar nominee Petra Costa as anti-Brazil activist. The Guardian, 4 fev. 2020. Disponível em: <https://www.theguardian.com/ world/2020/feb/04/bolsonaro-government-petra-costa-brazil-oscar-nominee>. Acesso em: 26 abr. 202.

PM TENTA impedir baile funk na Cidade de Deus e uma pessoa fica ferida - policiais militares informaram que foram atacados por criminosos. O Dia, Rio de Janeiro, 18 nov. 2019. Disponível em: <https://odia.ig.com.br/rio-de-janeiro/2019/11/5827869-pm-tenta-impedir-baile-funk-na-cidade-de-deus-e-uma-pessoa-fica-ferida.html>. Acesso em: 20 nov. 2019.

PM REPRIME bailes funk sem autorização. A Tribuna, Rio de Janeiro, 19 ago. 2019. Disponível em: <https://www.atribunarj.com.br/pm-reprime-bailes-funk-sem-autorizacao-em-sao-goncalo>. Acesso em: 6 out. 2019.

RANCIÈRE, J. O desentendimento. São Paulo: Ed. 34, 1996.

A partilha do sensível. São Paulo: Ed. 34, 2009.

REIA, J. et al. Entre regulações e táticas. Famecos. Porto Alegre: UNISINOS, v. 25, n. 3, 2018.

RIBEIRO, A. Homens lentos, opacidades e rugosidades. Redobra. Salvador: UFBA, n. 9, 2012, p. 58-71.

ROVENAT, F. 'Choradeira pura', diz Crivella sobre críticas ao carnaval do Rio. G1, Rio de Janeiro, 2 mar. 2018. Disponível em: <https://g1.globo.com/rj/rio-de-janeiro/noticia/choradeira-pura-diz-crivella-sobre-criticas-ao-carnaval-do-rio.ghtml>. Acesso em: 21 mar. 2020.

SÁ, S. P. de; CUNHA, S. E. Controvérsias do funk no Youtube. Eco-Pós. Rio de Janeiro, v. 17, n. 3, 2014. 
SALINAS, M. et al. Roda Cultural da Glória acontece na porta da Delegacia após repressão da polícia. Grito Filmes, 19 set. 2016. Disponível em: <https://www.youtube.com/ watch?v=I0AyqD0L-nA\&list=PLw8fmp6CkSJ6xs-Q17NJ0K7KPQjM98zNf>. Acesso em: 30 abr. 2020.

SANCHEZ, M. Pedra do Sal é interditada e comemoração do Dia da Consciência Negra na região é prejudicada. G1, Rio de Janeiro, 19 nov. 2019. Disponível em: <https://g1.globo. com/rj/rio-de-janeiro/noticia/2019/11/19/pedra-do-sal-e-interditada-e-comemoracao-do-dia-da-consciencia-negra-na-regiao-e-prejudicada.ghtml>. Acesso em: 21 nov. 2019.

SANTOS, M. A natureza do Espaço. São Paulo: EDUSP, 2002.

SILVA, R. V. Flows \& views: batalhas de rimas, batalhas de YouTube, cyphers e o rap brasileiro na cultura digital. 2019. Dissertação (Mestrado em Comunicação) - Instituto de Artes e Comunicação Social, Universidade Federal Fluminense, 2019.

SODRÉ, M. Samba, o dono do corpo. Rio de Janeiro: Mauad, 1998.

TABOADA, N. et al. Resiliência. Journal of Human Growth and Development. Marília (SP), v. 16, n. 3, 2006, p. 104-113.

TROTTA, F. Qual é o lugar do pagode no centenário do samba? E-Compós. Brasília, v. 22, 2019.

. Entre o Borralho e o Divino. Galáxia. São Paulo, n. 26, p. 161-173, 2013.

TURNER, V. Processo Ritual. Petrópolis: Vozes, 1974.

VENTURA, Z. Cidade Partida. Cia. das Letras, 1994.

VIANNA, H. O mistério do samba. Rio de Janeiro: Jorge Zahar, 1999.

VIDAL, L. Les Hommes Lents. Paris: Flammarion, 2020.

VIEIRA, T. Artivismo: estratégias artísticas contemporâneas de resistência cultural. 2011. Dissertação (Mestrado em Arte Multimédia) - Faculdade de Belas Artes, Universidade do Porto, 2011.

ZUMTHOR, P. Performance, recepção e leitura. São Paulo: Cosac \& Naify, 2007

Artigo recebido em 05/05/2020 e aprovado em 13/09/2020. 